\title{
KOMPETENSI PROGRAM STUDI DIPLOMA TEKNIK PERKAPALAN DALAM INDUSTRI MARITIM INDONESIA
}

\author{
Mohd Ridwan, EkoYulianto \\ Program Studi Diploma III Teknik Perkapalan \\ Fakultas Teknik Universitas Diponegoro
}

\begin{abstract}
Mohd Ridwan, Eko Yulianto, in paper competency of naval architecture diploma program on Indonesian maritime industry explain that Shipbuilding engineering professionals is part of the leading maritime industry is expected to become the motor of development of national maritime fleet in the implementation of cabotage (Impres No.5, 2005), this will reduce foreign exchange spending nearly 99 trillion rupiah per year due to the use of foreign fleets, and the creation of new jobs as a supporter of the maritime industry. So the presence of workers who have competence in the field of shipbuilding (ship building, naval architecture, marine engineering enginerring and maritime transportation) is urgently needed and their capability to compete with other countries that previously controlled the sea as a source of national income should be the Indonesian government's attention.
\end{abstract}

Keywords: Professional shipbuilding techniques, competency

\section{PENDAHULUAN}

Perkapalan merupakan bagian dari industri maritim yang menjadi tulang punggu transportasi laut khususnya bagi negara kepulauan. Walaupun transportasi laut merupakan kegiatan turunan dari sektor perdagangan antar pulau dan antar negaya yang telah terbukti memiliki keungulan komperatif sangat ekonomis (economics of scale) dalam menunjang perdangangan internasional sejak 3200 tahun sebelum masehi (Mesir).

Indonesia menjadi salah satu wilayah yang paling strategis dalam jalur pelayaran dunia (Mesir telah berhubungan dagang dengan Indonesia pada 1200 SM). Namun hal ini tidak menjadikan Indonesia menerima keuntungan dari kegiatan perdangan internasional tersebut. Kesempatan ini justru diambil oleh negara tetangan sperti Singapur dan Malaysia, mereka telah mampu menyediakan sarana pelabuhan yang menjadi Hub Port bagi armada kapal dunia.

Dapat kita bayangkan besarnya keuntungan yang diperoleh oleh dua negara tersebut karena $71 \%$ perdangangan Internasional menggunakan transportasi laut (sea borne trade), dimana dalam jumlah berat adalah berkisar $96 \%$ diangkut oleh armada kapal (moda laut). $70 \%$ dari transportsi laut untuk perdangangan Internasional melalui perairan Indonesia, artinya $70 \%$ dari armada kapal internasional menyinggahi hub port ke dua negara tersebut.

Sumber daya laut dapat dijadikan sebagai motor dalam pembangunan nasional dan dapat menjadi tumpuan untuk mensejahterakan bangsa. Namun kenyataan saat ini dari sisi transportasi laut, dapat dilihat bahwa armada kapal yang menjadi alat pemersatu bangsa dalam segi ekonomi Indonesia, masih sangat tergantung pada armada kapal asing ( $<50 \%)$.

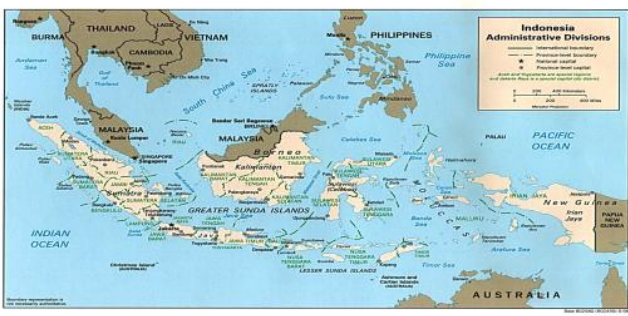

Gambar.1. Jalur pelayaran Indonesia

Melalui Inpres 5 tahun 2005 "asas cabotage" ("asas cabotage" adalah prinsip hukum yang dianut oleh sebagian besar negara maritim dunia yang menyatakan bahwa angkutan di dalam suatu negara hanya dapat diangkut oleh kapal yang berbendera dari negara yang bersangkutan ). Pemerintah Indonesia berkomitmen dan mengambil Kebijakan Kelautan (Ocean Policy) yang berpihak pada pembangunan ekonomi maritim. Kemudian ini ditindak lanjuti dengan langkah-langkah konkrit lanjutan menyangkut industri/ekonomi maritime

Kebijakan perkapalan, kepelabuh-an, transportasi laut dan antar moda, prioritas kegiatan ekonomi, kebijakan fiskal, kebijakan investasi, kebijakan energi, kebijakan dirgantara, kebijakan pembangunan daerah dan kawasan serta tatanan kelembagaan dan kebijakan pembangunan sumber daya manusia berpedoman pada visi dan misi maritim (bagian dari kebijakan kelautan).

Implementasi kebijakan kelautan memiliki dinamika dan tantangan, sebagai contoh : kebijakan pemerintah Thailand untuk merebut pangsa pasar transportasi laut dengan rencana membuat kanal di semenanjung Kra, hal ini akan mengurangi volume transportasi laut yang melalui perairan nusantara (Indonesia), yang merupakan tantangan bagi Indonesia selama membangun kekuatan ekonomi maritim sejalan dengan dinamika perubahan, dan komitmen kuat adalah kunci untuk membangun 
ekonomi berdaya saing (comparative), menciptakan pasar dalam negeri yang dapat berperan dalam ekonomi global.

Agar dapat bersaing dengan negara lain, Indonesia harus memiliki tenaga profesional atau sumber daya manusia andal yang memiliki kompetensi khususnya dibidang teknik perkapalan agar mampu mendukung pembangunan industri maritim terutama dalam hal pembangunan armada kapal nasional, dan menjadi tuan rumah di perairan laut Indonesia.

Selain pendidikan khusus di bidang perkapalan juga menciptakan kultur/budaya kemaritiman yang memiliki karakter dinamis dan sangat diperlukan karena khususnya armada kapal, memiliki sifat ekonomi, seperti : Nilai investasi tinggi yang beresiko tinggi, Jangka waktu panjang, Service life makin berkurang, Overaging (memperhatikan faktor keselamatan dan komersial).

\section{KONDISI PERKAPALAN NASIONAL}

Perairan Indonesia dengan letak geografi strategis, yaitu terletak pada jalur persimpangan $70 \%$ arus perdagangan dunia lewat laut (sea-borne trade), namun peran Indonesia sangat kecil dari angkutan komoditi perdangangan dunia tersebut yaitu hanya $0.69 \%$, dibanding negara tetangga (Malaysia $1.17 \%$ \& Singapura 2.66\%). Jumlah armada kapal yang terlibat 672 unit (554 nasional, 118 asing), dari 554 berbendera Indonesia namun sebagian besar adalah milik asing, hal ini dapat kita lihat dalam tabel 1 .

Tabel.1. Jumlah Unit Kapal Niaga dari beberapa Negara.

\begin{tabular}{lrrrrr}
\hline \multirow{2}{*}{ Negara } & \multicolumn{3}{c}{$\begin{array}{c}\text { Deadweight tonnage } \\
(\mathbf{x ~ 1 0 0 0 )}\end{array}$} & \multicolumn{2}{c}{$\begin{array}{c}\text { Persentase } \\
(\%)\end{array}$} \\
\cline { 2 - 6 } & \multicolumn{1}{c}{ Nas. } & Asing & Total & Nas. & Dunia \\
\hline China & 27.110 & 29.703 & 56.813 & 52,28 & 6,77 \\
Hongkong & 17.246 & 23.747 & 40.993 & 57,93 & 4,88 \\
Korea & 10.371 & 16.887 & 27.258 & 61,95 & 3,25 \\
Taiwan & 5.297 & 18.034 & 23.331 & 77,30 & 2,78 \\
Singapura & 12.424 & 9.909 & 22.333 & 44,37 & 2,66 \\
Malaysia & 6.054 & 3.781 & 9.835 & 38,44 & 1,17 \\
Indonesia & 3.660 & 2.094 & 5.754 & 36,39 & 0,69 \\
\hline \multicolumn{1}{c}{ Sumb }
\end{tabular}

Sumber:UNCTAD 2005

Dalam tabel 1 bahwa walaupun jumlah kapal Indonesia lebih banyak dari negara Malaysia (259 unit) ataupun Singapura (443 unit), namun kapasitas angkut per unit kapal kecil yaitu rata-rata 3.144 Dwt, sedangkan Malaysia 14.286 Dwt dan Singapura 38.033 Dwt.

Total jumlah armada kapal yang melayani angkutan di Indonesia baik dalam negeri maupun ke luar negeri adalah 1.405 kapal dengan total kapasitas adalah 4.416.795 Dwt, Namun yang menjadi perhatian disini adalah usia kapal tersebut, adalah : $0-4$ tahun $1 \% ; 5-9$ tahun $3 \% ; 10$ -14 tahun $6 \% ; 15-19$ tahun $5 \%$; 20 tahun keatas $85 \%$. Artinya $85 \%$ kapal Indonesia sudah saatnya untuk diremajakan dalam waktu dekat, dengan usia kapal tersebut jelas kemampuan armada nasional beberapa tahun kedepan akan turun dengan drastis.

Akibat rata-rata kapasitas angkut armada nasional kecil (3.144 dwt), maka armada kapal hanya melayani feeder port (port singapura, Malaysia: port klang \& Tanjung Pelepas) untuk angkutan ekspor impor (96\% dikuasai kapal asing, walaupun berbendera Indonesia), sehingga devisa yang menguap mencapai US\$.8miliar-US\$.9 miliar ditelan para operator pelabuhan asing tersebut.

Kapal berbendera asing yang menguasai bidang jasa angkutan dalam negeri mencapai angka $46,8 \%$ dan sisanya baru operator dalam negeri. Akibatnya, total devisa yang dikantongi kapal asing diperkirakan mencapai US\$ 11 miliar atau setara dengan Rp 99 triliun per tahunnya. potensi kemaritiman kita selalu dimakan orang lain. Ikan, contohnya. Menteri Perikanan menyebutkan, kita selalu rugi US\$ 2 miliar- US\$ 3 miliar per tahun karena ikan yang hilang di curi armada kapal perikanan asing

Pola perdagangan eksport/import menggunakan FOB/CIF (freight on bord / cost insurance freight) menyebabkan pihak luar negeri bebas menentukan armada angkutan laut yang akan mereka gunakan untuk melayani komoditi eksport/import tersebut. Hal ini dimungkinkan dengan bebasnya kapal asing masuk langsung kepelabuhan di Indonesia tanpa melalui Hub Port yang menjadi terminal komoditi eksport/import. Hal ini juga diperparah dengan kapasitas kapal per unit kecil dengan usia yang kebanyakan diatas 15 tahun.

Berdasarkan kondisi ini maka Pemerintah melalui departemen terkait telah memiliki komitmen untuk memberikan prioritas investasi untuk mengadaan armada kapal nasional (Radjasa. 2006). Pemerintah memproyeksikan investasi swasta di transportasi laut empat tahun mendatang mencapai $\mathrm{Rp} 326,59$ triliun atau 80,27\% dari total investasi swasta di sektor transportasi. Investasi laut sebesar itu, menurut Hatta, sekitar $99 \%$ atau sekitar Rp 323,36 triliun akan diprioritaskan untuk membangun armada kapal baru ataupun bekas.

Upaya ini sejalan dengan kebijakan pemerintah yang baru-baru ini mengeluarkan Instruksi Presiden (Inpres) No. 5 tahun 2005 tentang Pemberdayaan Industri Pelayaran Nasional, yakni dengan memberlakukan azas cabotage (kewajiban menggunakan kapal domestik di perairan nasional). "Dengan prioritas itu, alokasi investasi swasta untuk membangun armada kapal baru akan mencapai rata-rata Rp 64,673 triliun per tahun.”. Pemerintah juga berkomitmen, untuk program jangka pendek, yaitu : satu, pemerintah sedang mengupayakan kredit murah untuk meremajakan armada dalam negeri; Dua, akan 
merestrukturisasi peraturan perundang-undangan yang menyangkut pelayaran. Tiga mempersiapkan tenaga kerja profesional dalamg perkapalan baik untuk operator kapal, pelabuhan, dan bangunan baru serta reparasi kapal.

\section{PROSPEK PERKAPALAN PERDAGANGAN DUNIA}

DALAM

Kebutuhan kapal sebagai alat angkut moda laut yang sangat ekonomis di bandingkan dengan angkutan moda lain, terutama dipicu dengan meningkatnya harga minyak dunia menjadikan transportasi laut menjadi sangat dibutuhkan. Walaupun demikian kebutuhan transportasi laut dalam perdagangan dunia sangat tergantung pada besarnya volume perdagangan dunia lewat laut (seaborne trade) yaitu sebagai berikut.

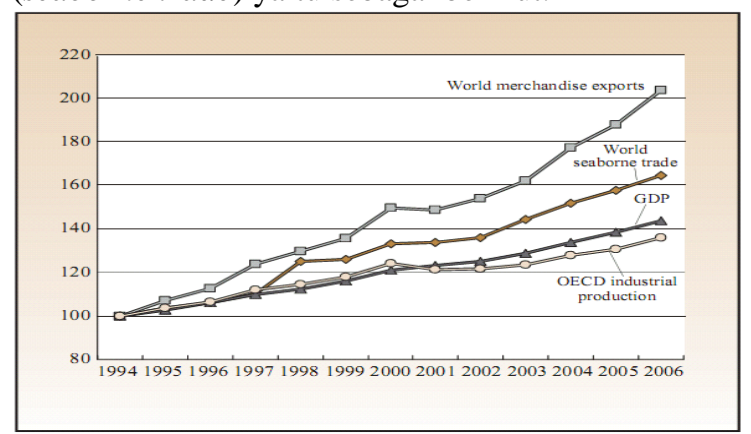

Gambar 2. Volume perdagangan dunia lewat laut (seaborne trade) Sumber : UNCTAD 2007

Ini didorong dengan meningkatnya perdagangan antar negara dalam era global dimana negara berkenbang dan sedang berkembang berpacu untuk meningkatkan aktivitas ekonominya rata $3 \%$ dan $6,7 \%$ (2006). Dalam waktu bersamaan peningkatan perdagangan menggunakan kapal dagang sebagai alat transportasinya adalah 8 $\%$ atau dua kali lipat pertumbuhan ekonomi dunia, sehingga permintaan angkutan laut selama tahun 2006 adalah 7.4 milliar ton. Pada transportasi laut angka tersebut menyebabkan peningkatan $5.5 \%$ atau 30.686 ton-mil.

Pelayaran dunia di awal tahun 2007 meningkat $8.6 \%$ yaitu 1.04 milyar deadweight tons (dwt) yang terdiri dari armada kapal tanker meningkat $8,1 \%$ dry bulk carriers $6,2 \%$ dimana ari dua type kapal ini menguasai hampir $72 \%$ dari total tonnage cargo dunia. Sementara itu general cargo meningkat $4.9 \%$ (2006) serta penigkatan paling tinggi adalag untuk tipe kapal container yaitu 15,5\% (17 juta dwt. Untuk memenuhi kebutuhan akan kapal ini telah dilakukan order untuk armada kapal baru dengan jumlah seperti ditunjukkan pada Gambar 3.

Jumlah tonnage kapal yang diorder sampai akhir 2006 adalah 302.7 juta dwt, (sebanyak 6.908 unit kapal) antara lain :

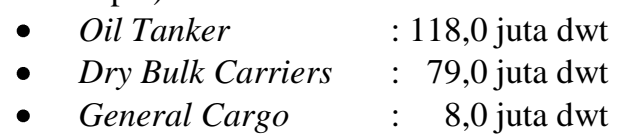

- Container Ship : 51,7 juta dwt

- Kapal jenis lain : 45,6 juta dwt

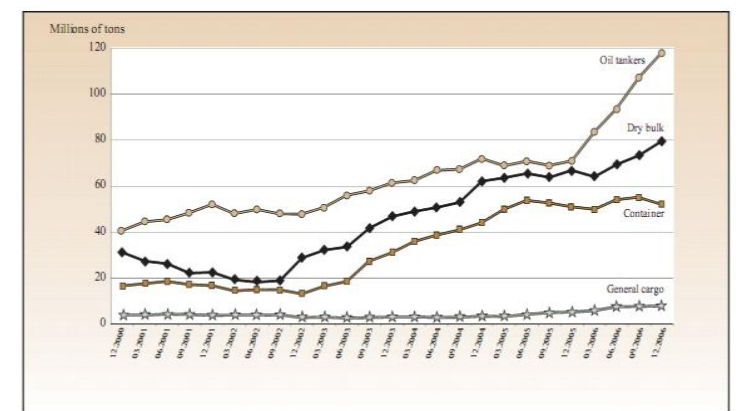

Gambar.3. Armada kapal dunia Sumber : UNCTAD 2007

Jumlah pesanan armada kapal akan bertambah sejalan dengan makin tua nya usia kapal yang sedang dioperasi saat ini yaitu rata-rata berusia 12 tahun, dengan kapal yang paling muda adalah container yaitu rata-rata 9,1 tahun, namun hampir 56,8 \% armada kapal berusia di atas 19 tahun, yang beberapa tahun kedepan harus diremajakan.

Dalam rangka meremajakan armada kapal dunia maka dibutuhkan Industri perkapalan yang andal dengan sumber daya manusia dan industri penunjang yang mampu dan memiliki kapasitas sesuai dengan perkembangan perdagangan dunia. Saat ini industri galangan kapal di negara asia timur yang menguasai suplai kapal dunia antara lain adalah :

- Hyundai Heavy Industries, Korea, world's Largest .

- Daewoo Shipbuilding \& Marine Eng. Korea, world's $2^{\text {nd }}$ largest.

- Samsung Heavy Industries, Korea, world's $3^{\text {rd }}$ largest.

- $\quad$ Aker Shipyard, Norway, World's 4.

- Waigaoqiao Shipyard, China, world \#1 (in 2015).

- $\quad$-Keppel Shipyard, Singapore, 17 yard's world. Sumber : LR's shipyard list

Sifat industri perkapalan di samping padat karya juga high technology menyebabkan negara maju yang memiliki soft skill tinggi tidak lagi merminat dalam bidang ini sehingga kesempatan bagi dunia yang sedang berkembang untuk menghasilkan devisa, dengan mengekspor produkproduk alat transportasi laut untuk mendukung perdagangan dunia.

Seluruh galangan kapal dunia diatas sudah memiliki order pembangunan kapal baru juga alatalat yang berhubungan dengan penambangan di laut. Sehingga dari galangan kapal di asia timur menguasai lebih $80 \%$ order pembangunan kapal dunia tersebut; dimana :

- $40 \%$ order kapal baru dunia dikuasai oleh Korea, dengan memiliki 3 galangan kapal yang terbesar di dunia dan fokus pada pembangunan 
kapal-kapal bernilai tinggi seperti kapal LNG, FSPOB, Chemical and oil tanker, dan menjadikan industri perkapalan sebagai industri strategis, didukung oleh pembangunan sumber daya manusia dan Industri penunjang beserta finacial yang baik.

- $24 \%$ order kapal juga dikuasai oleh negara Jepang, industri perkapalan merupakan industri strategis yang didukung dengan sumberdaya manusia dimana, sebagian besar diambil dari program kerja magang bekerjasama dengan negara yang sedang berkembang, sperti Pilipina, Indonesia dan negara di Asia lainnya. Disamping hal itu industri perkapalan Jepang telah mampu menghasilkan kapal dengan kualitas dan teknologi tinggi, produktivitas konstan dengan skala besar.

$14 \%$ dikuasai oleh China, sebagai negara dengan jumlah tenaga kerja yang banyak dan gaji sangat murah, mereka mampu membangun kapal kapal bulk carriers, didukung dengan kebijakan pemerintah yang memihak pada pengembangan industri perkapalan

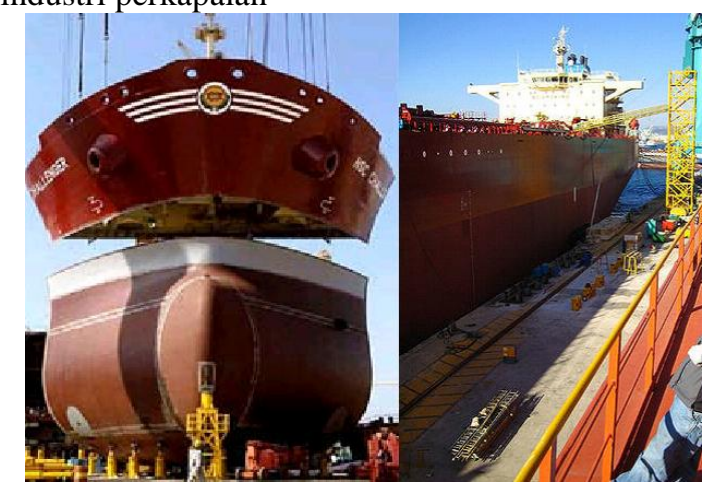

Gambar.4. Industri perkapalan (shipyard)

Kontrak pembangunan kapal baru ini, dengan ukuran rata-rata: 14.000 TEU's (container ship) dan VLCC 300.000 dwt (very large croude oil carriers), dilakukan oleh pihak galangan kapal dengan pemilik kapal yang kebanyakan berasal dari negara Eropa dan Asia antara lain ;

Tabel. 2 Negara yang mendominasi armada kapal dunia

\begin{tabular}{lc}
\hline \multicolumn{1}{c}{ Negara } & x 1.000.000,- DWT \\
\hline Greece & 166 \\
Japan & 138 \\
Germany & 81 \\
China & 67 \\
Norway & 46 \\
US & 45 \\
Hongkong (China) & 44 \\
Korea & 31 \\
Singapore & 24 \\
UK & 22 \\
\hline
\end{tabular}

Sumber: Unctad

\section{PROSPEKTUS SDM BIDANG PERKAPALAN INDONESIA}

Dengan semakin besarnya permintaan armada kapal baru dunia terutama untuk kapal kontainer dan tankers, maka tidak salah indonesia juga harus bisa mengambil bagian dalam industri perkapalan tersebut, disamping sangat strategis, indonesia sebagai negara kepulauan sudah mengenal kapal sejak zaman kerajaan Sriwijaya dan pelaut-palaut Nusantara terkenal sangat andal.

Kondisi armada kapal nasional saat ini sudah mulai tua sehingga dalam lima tahun kedepan sudah harus diganti dengan yang baru , sementara itu dengan di berlakukannya asas cabotage maka jumlah kapal yang berbendera Indonesia akan terus di perbanyak untuk dapat melayani perdagangan ekspor/impor Indonesia maupun antar pulau.

Data terakhir (dari berbagai sumber) menunjukan bahwa share Transportasi Laut Luar Negeri Armada Nasional hanya mencapai 5,6 \% dari total muatan sebesar 345 juta ton, sedangkan untuk Transportasi Laut Dalam Negeri hanya mencapai $46.4 \%$ dari total angkutan 170 juta ton (perkembangan market share untuk angkutan laut dapat dilihat dalam grafik pada Gambar 5).

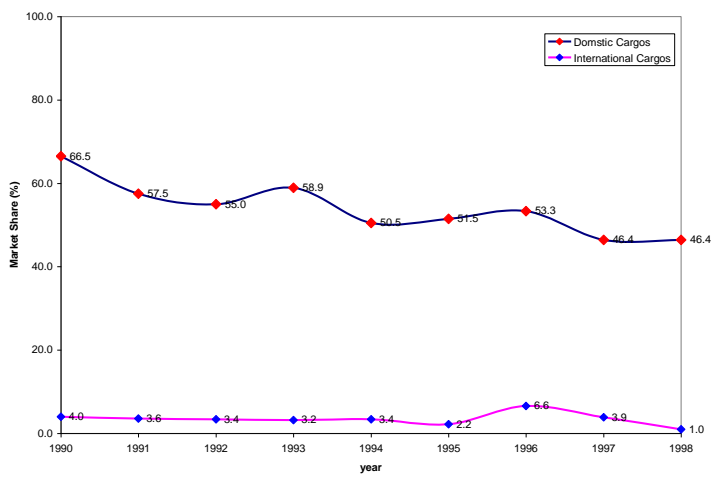

Gambar.5. Grafik perkembangan market share armada nasional (sumber : Dephub)

Armada kapal nasional baru mencapai 2.53 $\%$ dari total armada kapal Asia $(0.61 \%$ armada dunia), masih jauh di bawah dari beberapa negara di Asia, yang dapat di lihat dari tabel .3.

Bagi negara kepulauan seluas Indonesia, kegiatan transportasi laut merupakan tulang punggung untuk merealisasi cita-cita yang dikandung di dalam azas Wawasan Nusantara dan mewujutkan masyarakat adil dan makmur, sehingga kekuatan armada kapal nasional perlu di tingkatkan, agar dapat berkompetisi dengan negara lain terutama dalam menraih muatan perdagangan dunia. 


\begin{tabular}{|c|c|c|c|c|c|c|c|}
\hline $\begin{array}{l}\text { Coustryterritory } \\
\text { or grouping }\end{array}$ & Type & $\begin{array}{c}0=4 \\
\text { yearx }\end{array}$ & $\begin{array}{c}5-9 \\
\text { years } \\
\end{array}$ & $\begin{array}{l}10-14 \\
\text { years } \\
\end{array}$ & $\begin{array}{l}15-19 \\
\text { years } \\
\end{array}$ & $\begin{array}{c}20 \text { years and } \\
\text { over }\end{array}$ & Average age \\
\hline \multirow[t]{6}{*}{ Indonesia } & Bulk carriers & 3.5 & 0.0 & 8.8 & 11.8 & 75.9 & 21.0 \\
\hline & Cosstainerstlips & 2.8 & 22.4 & 4.2 & 5.6 & 65.0 & 18.3 \\
\hline & Citncral eargo & 2.5 & 0.7 & 4.5 & 4.7 & 87.6 & 22.0 \\
\hline & Oil unkers & 2.4 & 2.2 & 12.3 & 3.5 & 79.5 & 21.0 \\
\hline & Other types & 4.2 & 5.0 & 14.6 & 11.7 & 6.5 & 19.3 \\
\hline & All & 2.8 & 3.1 & 8.3 & 5.8 & 80.1 & 21.1 \\
\hline \multirow[t]{6}{*}{ Singapore } & Bulk carriers & 26.5 & 22.1 & 28.2 & 16.5 & 6.7. & 9.8 \\
\hline & Contzinerships & 220 & 27.9 & 29.2 & 11.0 & 9.8 & 10.1 \\
\hline & Genenal eargo & 20.6 & 14.4 & 14,7 & 3,7 & 46.3 & 14.8 \\
\hline & Q1 tankers & 202 & 14.9 & 18.1 & 30.3 & 16.7 & 12.7 \\
\hline & Oher rypes & 32.5 & 15.3 & 9.6 & 8.5 & 342 & 12.3 \\
\hline & & 22.5 & 18.0 & 211.1 & 225 & 159 & 11.8 \\
\hline \multirow[t]{6}{*}{ Malay sia } & Bulk carriers & 14.7 & 32.6 & 25.5 & 6.8 & 20.4 & 11.6 \\
\hline & Containerships & 14.1 & 300 & 18.8 & 19.0 & 18.0 & 12.1 \\
\hline & General cargo & 3.8 & 3.1 & 11.4 & 6.4 & 75.4 & 20.5 \\
\hline & Oil tankers & 41.6 & 22.1 & 9.9 & 14.7 & 11.6 & 8.8 \\
\hline & Otber typs & 28.7 & 11.0 & 20.7 & $3, \mathrm{~A}$ & 36.1 & 12.9 \\
\hline & All & 31.0 & 19.4 & 14.8 & 11.0 & 23.8 & 11.2 \\
\hline
\end{tabular}

Untuk dapat mewujudkan Transportasi laut yang handal dan kredibel, maka perlu dilengkapi dengan sarana dan prasarana yang memadai dan handal pula, dibarengi dengan kebijakan-kebijakan yang menunjang serta diterjemahkan ke dalam bentuk peraturan-perundangan yang komprehensif dan pragmatis. Oleh karena itu, merupakan kewajiban kita untuk menata Sub Sektor Perhubungan Laut/Maritim demi kejayaan Bangsa dan Negara, yang meliputi Aspek maritim di bidang : Angkutan Laut, Kepelabuhanan, Navigasi, Keselamatan apal dan Pelayaran, Lingkungan Maritim dan Pencemaran Laut, SDM, Hukum dan Kerjasama Internasional, dan bersinergi dengan industri penunjang lainnya, serta yang tak kalah penting untuk mewujutkan hal di atas adalah kebijakan pemerintah berupa dukungan financial dan fiskal yang memihak pada bidang transportasi laut.

Dukungan Finasial dan Sumberdaya Manusia bidang perkapalan merupakan faktor yang sangat menentukan bagi terwujudnya peran armada nasional dalam melayani pengembangan perdagangan (ekonomi) Indonesia dengan pihak internasional dan antar pulau di dalam negeri. Dengan melihat sifatnya yang padat modal, padat karya, melibatkan berbagai macam infrastruktur dan sektor lainnya yang saling terkait, serta faktor permintaan derifative pada sektor angutan laut, menyebabkan sektor maritim memiliki resiko yang tinggi bagi investasi. Namun hal ini dapat dieliminasi dengan penguasaan terhadap persoalanpersoalan kemaritiman khususnya sektor ankutan laut serta di jamin dengan kebijakan yang memihak, maka resiko investasi tersebut dapat diminimalis, dan memberikan keuntungan jangka panjang yang jauh lebih baik dari industri darat lainnya.

Institusi yang melibatkan sumberdaya perkapalan dalam sektor transportasi/ angkutan laut ini, terdiri dari tiga bagian, yaitu : pemilik angkutan (carrier), Operator infrastruktur dan fasilitas pendukung (non-carrier), dan architectur transportasi cargo (freight forwarder), serta institusi pendukung :

1. Pemiliki angkutan (carriers).
a. Pemilik kapal (ship owner).

b. Perusahaan agen pelayaran dan operator kapal.

c. Operator angkutan jalan, kereta api dan udara.

2. Operator infrastruktur dan fasilitas pendukung (non-carriers)

a. Operator Terminal (laut dan udara),

b. Operator gudang

c. Operator depot / pelabuhan kering / kargo konsilidasi (CFS, container freight station.)

d. Perusahaan packaging, dll

e. Galangan Kapal (shipyard)

3. Freight forwarder, merupakan artsitek/perencana angkutan barang, yang biasa bertindak sebagai pemilik barang (on behalf shipper or consignees), dan bertangung jawab dalam seluruh proses transportasi barang, mulai dari perencanaan, dokumentasi, pengontrolan dan pengamatan sampai barang diterima di tempat tujuannya.

4. Institusi Pendukung

a. Asuransi, Karantina, Bea cukai

b. Perbankan, Lembaga keuangan non bank lainnya

c. Teknologi Informasi (IT system).

d. Lembaga pendidikan Perkapalan dan Pelayaran

e. Biro klasifikasi kapal, dll

Hal di atas menunjukan betapa luasnya sektor yang akan melibatkan SDM perkapalan sepuluh tahun kedepan, terutama jika kita lihat jumlah kapal baru yang harus dibangun agar kebijakan cabotage dapat di terapkan adalah 6.392.000,- dwt jika rata 1 unit kapal (10.000 dwt) maka jumlah kapalnya adalah 630 unit.

Dalam satu proyek pembangunan kapal tenaga profesioanl yang dibutuhkan dapat kita lihat pada struktur organisasi manajemen pembanguanan kapal baru sebagai berikut :

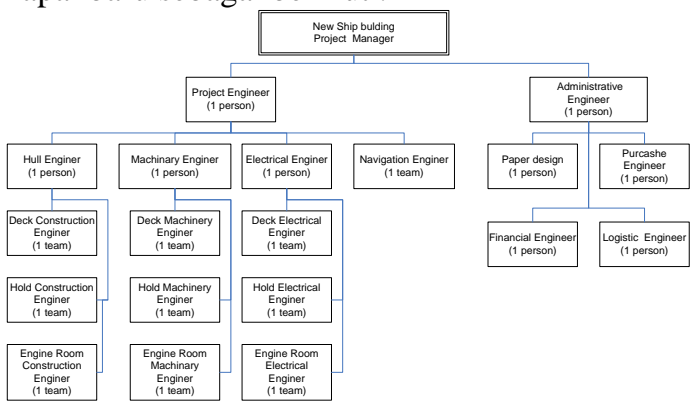

Gambar.6. Struktur Organisasi Proyek Pembanguan Kapal baru.

Project manager, project Engineer, dan Administrative Engineer dibutuhkan SDM yang berpengalaman dan profesioanal dengan strata pendidikan minimal Diploma IV Teknik Perkapalan, Kemudian setingkat dibawah manager dengan SDM minimal memiliki pengalaman dan pendidikan Diploma III Teknik Perkapalan, serta 
team dibawahnya dengan Pengawasan dan pelaksana dengan SDM berpendidikan Diploma III Teknik Perkapalan dibantu dengan tenaga terampil berpendidikan menegah atas.

Degan demikian akan dibutuhkan SDM Teknik perkapal dengan tingkat profesional (memiliki keahlian dan keterampilan) untuk membangun satu unit kapal baru pertahunnya ratarata 100 orang, sehingga jumlah total untuk membanguan armada kapal nasional di perkiraaakan 6000 orang SDM.

Sementara ini Pendidikan profesional teknik Perkapalan yang diselengarakan oleh UNDIP sejak 1976 baru menghasilkan 1500 orang. Sesuai dengan perkembangan teknologi dan ilmu pengetahuan dibidang perkapalan, kompentensi lulusan diploma teknik perkapalan harus di tingkatkan minimal memiliki sertifikasi profesi seperti : Welding Insspector, Welding Enginer, Hull and Machinery Designer dengan penguasaaan software applikasi Teknik Perkapalan.

SDM Dengan kompetensi Teknik perkapalan ini juga dibutuhkan oleh bidang lain selain bidang utama (new bulding and repair) pada galangan kapal seperti :

- Owner Surveyor dan Marine Engineer pada perusahan pelayaran

- Shiping Estimator Engineer pada perusahaan keuangan, seperti : Perbankan dan Asuransi.

- Marine Inspector pada perusahaan klasifikasi dan lain-lain.

- Marine Transport Engineer pada perusahaan transpotasi, serta perusahaan yang membutuhkan transportasi laut seperti perusahaan pertambangan, Anjungan lepas pantai, perikanan laut, dan lain-lain.

\section{KESIMPULAN}

Potensi sumber daya laut 2,7 juta $\mathrm{m}^{2} \mathrm{ZEE}$ Indonesia, harus dimanfaatkan sebagai tulang punggung pembangunan nasional, degan demikian peran bidang maritim, menjadi sangat strategis dalam mempercepat proses pembangunan. Peningkatan pembangunan nasional dapat dilihat dari tingkat pertumbuhan ekonomi, yang di tandai dengan meningkatnya nilai ekspor-impor nasional Indonesia. Komoditi ekspor dari Indonesia pada umumnya adalah sumber daya alam berupa hasil pertanian, perikanan, dan hutan, serta sebagian kecil industri darat.

Kelancaran kegitan eksport-impor yang memegang peranan penting adalah transportasi laut, namun sampai saat ini Indonesia masih mengalami defisit dari penyediaan jasa transportasi laut, sehingga perlu dipacu dengan kebijakan pemerintah baik berupa peraturan (cabotage), dan pendanaan yang berdapat memacu industri transportasi laut untuk memperkecil atau bahkan memberi keuntungan/income bagi negara.

Armada kapal nasional Indonesia baru mencapai $2.53 \%$ dari total armada kapal Asia $(0.61 \%$ armada dunia). Keterpurukan dalam pelayaran juga lebih banyak diakibatkan kondisi armada yang sudah berumur dan berukuran kecil, sehingga armada tersebut perlu diperbaharui, serta dibutuhkan industri maritim yang dapat membangun armada kapal baru ataupun reparasi kapal, beserta SDM dengan industri penunjang baik komponen kapal, pendanaan, dan pelayaran. SDM yang dibutuhkan disini memiliki keahlian dan keterampilan (profesional) yang spesifik di bidang teknik perkapalan, dengan jumlah 6000 tiap tahunnya.

SDM Teknik Perkapalan dibutuhkan dalam satu poyek pembangunan kapal baru dengan Posisi Spesifik antara lain : Project manager, project Engineer, dan Administrative Engineer ditempati oleh SDM yang berpengalaman dan profesioanal dengan strata pendidikan minimal Diploma IV Teknik Perkapalan, Kemudian setingkat dibawah manager dengan SDM minimal memiliki pengalaman dan pendidikan Diploma III Teknik Perkapalan, serta tim kerja dibawahnya dengan Pengawasan dan pelaksana, oleh SDM berpendidikan Diploma III Teknik Perkapalan dibantu dengan tenaga terampil berpendidikan menegah atas yang berlatar pendidikan Teknik Perkapalan.

Untuk menghasilkan profesional bidang teknik perkapalan dibutuhkan pendidikan dan pelatihan khusus setingkat diploma teknik perkapalan, ditunjang dengan workshop dengan peralatan yang kredible, dengan sifat bidang perkapalan dinamis dan menglobal maka SDM yang dihasilkan dapat bekerja di perusahaan dalam negeri mapun luar negeri, dan berpotensi untuk menekan defisit negara dari sektor transportasi laut (11 milyar US\$ per tahun).

\section{DAFTAR PUSTAKA}

1. Prayudyanto M Nanang, 2004, Procurement Armada Pelayaran Nasional, Jakarta.

2. Ridjin ketut, 2003, Pengantar Perbankan Dan Lembaga Keuangan Bukan Bank,Gramedia, Jakarta.

3. Robert Kodoati, Ekonomi Teknik, Semarang

4. Sasono Djoko, 2003, Multimodal Transport Development In Indonesia', research \& Development center for MTM, ministry of communications, Indonesia.

5. Stopford Martin, 2000, Maritime Economics, second edition, London.

6. Untacd, 2007, Maritime Transportation Report, New York. 